\title{
Endovascular remodeling of tortuous cervical segments of the internal carotid artery that hinder the management of complex intracranial aneurysms
}

\author{
Marco Antonio Zenteno ${ }^{1}$, Jorge Arturo Santos-Franco ${ }^{2}$, \\ Luis Rafael Moscote-Salazar ${ }^{3}$, Ángel Lee ${ }^{4}$
}

${ }^{1}$ Chairman of the Department of Neurological Endovascular Therapy of the Instituto Nacional de Neurología y Neurocirugía "Manuel Velasco Suárez”. Profesor of Neurological Endovascular Therapy at the Universidad Nacional Autónoma de México. Comprehensive Stroke Unit, Hospital Ángeles del Pedregal; ${ }^{2}$ Department of Neurosurgery at the Centro Médico Nacional "La Raza". Assistant Professor in Neurosurgery at the Universidad Nacional Autónoma de México. Mexico D.F.;

${ }^{3} \mathrm{MD}$, Universidad de Cartagena, Cartagena de Indias, Colombia;

${ }^{4}$ Comprehensive Stroke Unit, Hospital Ángeles del Pedregal. Department of Neurosurgery, Instituto Nacional de Ciencias Médicas y Nutrición, Salvador Zubirán, Mexico City, Mexico.

\begin{abstract}
Introduction: Severe tortuosity of the cervical segment of the internal carotid artery (ICA) may hamper the navigation of intravascular devices for the management of complex intracranial aneurysms and even conventional techniques of ICA access can fail. In a group of selected cases, we analyzed the efficacy and safety of carotid stenting to straighten the Severe tortuosity for direct navigation of the devices.
\end{abstract}

Methods: A case series of 16 patients harboring 18 intracranial aneurysms with a difficult endovascular approach because of a cervical ICA with Severe tortuosity were prospectively recruited at our institution from January 2005 to December 2007. When traditional means of correction could not surmount this obstacle, an overlap stenting with a distal-to-proximal technique was used to overcome the Severe tortuosity.
The efficacy of the procedure was defined as the ability to reach and be able to treat the target lesion with a smooth navigation of the endovascular devices. Safety was documented by procedure-related complications.

Results: The straightening of the vessel by the stent helped to overcome pitfalls, making possible an obstacle-free navigation of the endovascular devices to the target lesion in all cases. In 5 cases with severe or double kinking, a distal transfer of the curve beyond the stent was observed, without impact on the efficacy of the procedure. One case of periprocedural related technical complication occurred with a permanent stroke. During the follow-up period (22.7 \pm 8.4 months) no case of stent-related stroke or severe hyperplasia was observed.

Conclusions: Carotid stenting is an available option when a cervical ICA with Severe tortuosity hampers a smooth 
catheterization of the intracranial circulation, in carefully selected cases. It allows a relatively safe and free navigation and/or deployment of additional endovascular devices needed for the treatment of complex intracranial aneurysms.

Key words: Carotid stenting, carotid kinking, guiding catheter stability, intracranial aneurysm, carotid tortuosity, overlapping stenting.

\section{Introduction}

Endovascular treatment is an accepted worldwide method for the management of intracranial aneurysms, most of the lesions are now amenable to this kind of treatment $(1,2)$. A subgroup of complex lesions require the use of special techniques as balloon-remodelling (3), stent-assisted coiling $(2,4,5)$ or sole stenting (6-9), thus enlarging the application of endovascular therapy to those challenging lesions.

Successful navigation with use of the aforementioned techniques is usually possible; however, in some patients, the navigability, trackability and deliverability of these devices can be hindered by excessive vascular intracranial tortuosity $(5$, 10-13). In fact, failed attempts for coiling the targeted lesions can be up to $16 \%$, mainly because of the inability to catheterize the aneurysm. (32) The issue of the extracranial tortuosity is not less important (14). Guiding catheters have progressively improved their flexibility while maintaining sufficient stability at their distal end, with sufficient back-up support $(14,15)$; however, this advantage is difficult to accomplish in cases of kinked or very tortuous extracranial ICA.

Some newer guiding catheters have been introduced, but still have some limitations especially when an assisted coiling is required. The recent technical improvements of intracranial stents have not completely resolved the problem of navigability in cases of hostile extracranial anatomy. (52, 53) Transitory endovascular strategies to straighten this kink have been devised (double-wire and coaxial doubleguiding catheter technique) $(15,16)$, but are sometimes not sufficient to allow easy navigation or delivering the devices at the intended position, representing additional manipulations, carrying the risks of cause dissection and occlusion/subocclusion of the artery $(17,18)$. Other strategies have been described, as the direct puncture of the ICA $(10,19)$ or cut-down techniques with surgical exposure of the artery (17, 20). These maneuvers are not devoid of complications and seem not easy in distal kinkings. Carotid stenting is now widely used in the management of atherosclerotic cerebrovascular disease with safety (21-24), however, the use of this technique to provide straightforward access to the intracranial aneurysms and avoid potential complications has never been described.

The goal of this paper is to present the results of a case series of selected complex intracranial aneurysms with a failed access using traditional strategies, and requiring the correction of extracranial K-T for successful treatment.

\section{Material and methods}

\section{Study design and patient selection}

This is a prospective case series of patients harboring intracranial aneurysms of the anterior circulation who underwent endovascular straightening of the K-T of the cervical ICA to enable safe embolization of the target lesion. The patients were consecutively recruited in a period 
encompassing from January 2005 to December 2007. The study was conducted following the Guidelines for Reporting Observational Studies. (50)

Demographic features and previous medical history were recorded. The aneurysms were classified according to their clinical presentation into: ruptured (acute or previous hemorrhage) and non-ruptured (either incidental or symptomatic). The patients with subarachnoid hemorrhage (SAH) were assessed using the Hunt and Kosnik scale (25), while the rest were evaluated using the modified Rankin scale (mRS) (26).

\section{Preprocedural imaging assessment}

Prior to their enrollment, all the patients were assessed by digital subtraction angiography (DSA) using a 3D AXIOM Artis dBA (Siemens Medical Systems, Erlangen, Germany) and morphologic evaluation and measurements of the parent vessel were done on a separate workstation by using reconstructed 3D-DSA images (Leonardo workstation).

For the evaluation of the tortuosity, the angiographic projection with the best visualization was chosen and was measured by drawing a midaxis line of the involved vessel in the segments proximal and distal to the tortuous segment (27). The intersection of both lines allowed measuring the angle. The elongation of the internal carotid artery (ICA) was defined according to preestablished criteria $(28,29$, 46, 47, 48, 49, 50, 51, 52).

Aneurysms. Intracranial aneurysms were classified according to their size, location, shape, and site of origin. Regarding size, the universal criteria for small, large and giant were kept. Neck size and dome-neck ratio were also noted.
Technical obstacles leading to the indication of stenting. They were categorized as follows:

1) inability to cross the kinked segment 2) partially obstructing guiding catheter 3) instability/excessive mobility of the guiding catheter, 4) unstable or difficult navigation/delivering/deploying an intracranial of intracranial devices (e.g., coils).

The difficulty to straighten the kinked vessel was foreseen according to the supplementary maneuvers that were required. Either a hydrophilic 0.038 " or 0.035 " guidewire was capable of correcting the vessel, or in some cases, a single supportive guidewire or a double supportive "buddy" guidewire was needed.

\section{Endovascular procedure}

Carotid stenting. The morphologic evaluation and measurements of the parent vessel allowed the planning of the strategy and the choice of tailored devices. An $8 \mathrm{~F}$ guiding catheter (Guider, Boston Scientific, Fremont, CA) was placed in the common carotid artery via the femoral route.

In all cases, a transitory correction of the kinking was attempted by using a 0.035 " or 0.038 " hydrophilic guidewire, stiff 0.014 " guidewires (30) or a double supportive "buddy" guidewire.

Once the vessel has been transitorily "straightened" with these methods, a selfexpanding stent (Wallstent, Boston Scientific, Natick, Ma.) is navigated to the desired position. No protection devices were employed.

The planned technique was to deploy the first stent as distally as possible in the ICA (transition to petrous segment) and to place a second stent proximally with an overlapping technique. In certain cases, 
additional stents were necessary until the kinking resolved completely.

Once the stent was deployed, tirofiban Aggrastat $^{\mathrm{TM}}$ ) was prescribed in all cases at a conventional dosage of $0.4 \mu \mathrm{g} / \mathrm{Kg} / \mathrm{min}$ for half an hour and $0.1 \mu \mathrm{g} / \mathrm{Kg} / \mathrm{min}$ for the next 24 hours. Later on, the treatment was switched to a double oral regime with clopidogrel $75 \mathrm{mg}$ qd and aspirin $100 \mathrm{mg}$ qd for the next 6 months $(7,8,31)$.

Management of the aneurysms. They were treated with the required strategy for the corresponding parent vessel-aneurysm complex pattern: simple coiling, stentassisted coiling or sole stenting. The navigability of the devices and the percentage of occlusion were noted.

Efficacy and safety of the procedure. The procedure was considered technically successful whenever the guiding catheter permitted independent coaxial mobility of the device contained therein and a successful navigation/delivery/deployment of the intended devices and inadequate when the ancillary procedure did not allow a better result when treating of the target lesion.

The procedure-related complications were categorized as follows: access siterelated complications, hemodynamic effects (hypotension, bradycardia), and neurological impairment (classified as transient, reversible or permanent) (14).

\section{Clinical and imaging follow-up}

Every single patient was clinically assessed at discharge and at $3^{\text {rd }}, 6^{\text {th }}$ and $12^{\text {th }}$ months using the mRS (26). The aneurysm and the stents were assessed by DSA at 3, 6 and 12 months.

\section{Statistical analysis}

We employed descriptive statistics with measures of the central tendency and dispersion ( \pm standard deviation) in case of continuous variables and proportions and percentages in nominal variables. Non parametric inferential statistic for nominal or ordinal variable was applied ( $\chi 2$ or exact Fisher test), using SPSS statistical package (SPSS, Chicago, IL), the level of significance was set at a probability value of less than 0.05 .

\section{Ethical considerations}

The decision was jointly taken with the Department of Neurosurgery. All the patients either did not qualify or refused neurosurgical treatment. A written informed consent form was obtained from all the patients and/or their relatives, in accordance with established protocols by our institutional Committee of Ethics and with the Declaration of Helsinki.(54)

\section{Results \\ Clinical and imaging features}

Over a period of 3 years a total of 286 patients with cerebral aneurysms were treated, we found 40 (14\%) patients with kinking and 32 (9\%) with tortuosity of the cervical ICA, from these subgroups, 16 patients $(5.6 \%$ of the total) underwent endovascular stenting of the ICA tortuosity carotid with 18 corrected arteries. The sex ratio was of 7:1 for a female predominance, with a mean age of $62 \pm 7.8$ years. The only relevant fact in their past medical history was systemic hypertension in 6 cases (43\%).

Aneurysms. They were all saccular and only one case of recent acute rupture was included (Hunt and Kosnik grade 3). In the group of non-ruptured cases, 7 (38\%) were incidental, 7 (38\%) presented with cranial nerve compression and $3(16 \%)$ were seen because of a previous rupture of another aneurysm. They were located in the supraclinoid ICA in 16 (88\%) of the cases 
and two (11\%) on the anterior communicating artery. Concerning size, 8 (44\%) were large and $3(16 \%)$ were giant. The average neck size was of $6,4 \mathrm{~mm}( \pm 3$, 4) and dome-neck ratio was below 2 in 15 $(83 \%)$ cases. Five patients harbored multiple aneurysms.

Kinking features. The kinking was mild in $8(44 \%)$, moderate in $5(27 \%)$, and severe in $3(16 \%)$ cases. Tortuosity was present in only $2(11 \%)$ cases. Tandem or double kinkings were found in $5(27 \%)$ of the cases.

Technical obstacles leading to the indication of stenting. Some of them may coexist in the same vessel, and according to the aforementioned categories, their relative frequency was as follows: 1) inability to cross the kinked segment was observed in 3 $(16 \%)$ 2) a partially obstructing guiding catheter was present in $4(22 \%)$ cases, 3$)$ the instability/excessive mobility of the guiding catheter existed in $3(16 \%)$ arteries, 4) the instability/difficult navigation of intracranial devices (e.g., coils) was encountered in 3 $(16 \%)$ cases, and 5) difficulties in delivering/deploying/stabilizing an intracranial stent $10(55 \%)$ of the total.

\section{Procedure}

Carotid stenting. A carotid Wallstent (Boston Scientific, Fremont, CA) was used in all patients and a single 0.014" microguide wire (ChoIce ${ }^{\circledR}$ PT Extra Support Guide Wire, Boston Scientific, Fremont, CA) in most cases (10/18) 55\%. In three patients an additional "buddy" microguide wire was necessary to provide an extra support, when a marked or a double kinking was present. In two cases a single stent was used, but the kinking was transferred beyond the stent. From then on, the aforementioned distal-to-proximal stenting technique was employed. Two stents were used in 11 (61\%) cases, and three $(16 \%)$ stents in 5 arteries. According to the aforementioned convention, all the arteries were satisfactorily corrected providing sufficient stability allowing a successful treatment of the target lesion, specifically facilitating the navigation of the microcatheter into the sac, sufficient packing of the aneurysm and the deployment of the intracranial stent in all cases. When considering the angiographic result, a complete correction was seen in 13 $(72 \%)$ cases and a distal transfer of a curve in $5(27 \%)$ of the cases, especially when a severe or double kinking was present. (Fisher's Exact Test, 2-sided, P = 0, 047).

Complications. No hemodynamical effects were seen. There was one case of postoperative groin hematoma. In another case, the stent was misdeployed producing an ICA dissection. The aneurysm was coiled and subsequent intraarterial and mechanical vascular rescue were attempted, with partial recanalization. The patient presented a left opercular stroke with residual aphasia, which was rehabilitated thereafter.

Aneurysm management. Stent-assisted coiling was the commonest strategy of treatment, either with a self-expandable stent (SES) in 10 cases (55\%) or with a balloon-expandable stent (BES) in 5 cases (27\%). SES were Neuroform3 stents (Boston Scientific, Fremont, CA) and BES were Pharos stents (Micrus Endovascular, Sunnyvale, CA). Three patients underwent a single coiling procedure and another two a sole stenting procedure. There was only one case of an acutely ruptured aneurysm which was partially coiled first, with a further stent-assisted coiling which required a stenting of the cervical carotid artery. 
Complications. One patient presented angiographic occlusion of a distal branch due to the treatment of the aneurysm. The clot resolved after intravenous glycoprotein $\mathrm{IIb} / \mathrm{III}$ receptor antagonist therapy. No clinical or imaging evidence of stroke could be shown.

\section{Follow-up}

The mean clinical follow-up period was of $22.7 \pm 8.4$ months (range: $8-40$ months). At 6 months follow-up, the mRS was of 0 to 2 in 16(88\%) patients, and mRS 3 in two patients, one stroke due to cerebral vasospasm, and other case of procedurerelated stroke (stent placement). An asymptomatic intimal hyperplasia occurred in two cases.

\section{Discussion}

Cervical tortuosity can limit endovascular approach (32). Cai et al treated 63 patients for ruptured and unruptured aneurysms, 10 patients required direct carotid puncture, and in other 3 cases, selective embolization of the aneurysm failed as the result of vessel tortuosity (32). Technical limitations because of the anatomy of the cervical ICA and the anterior bend of its cavernous segment also affected 2 in another series of 36 patients scheduled for endovascular management of an intracranial stenosis (33).

Severe tortuosity, Kinkings and intracranial aneurysms. In angiographic series, a kinking of the cervical ICA is present in 15 to $25 \%$ of the subjects (28, 34). To our knowledge, there is no report specifying how the coexistence of intracranial aneurysms and ICA Severe tortuosity is frequent. However, in our multicenter/institutional series of intracranial aneurysms $(\mathrm{n}=286)$ this association yielded an overall frequency of $14 \%$.

The principal technical obstacles due to Severe tortuosity of the ICA were categorized in five groups:

1) inability to cross the kinked segment is the first obstacle. Ideally, the guiding catheter should be positioned as close of the skull base as possible to maintain a good support to navigate any endovascular device to the intracranial circulation (12). However, in certain cases, a standard guiding catheter cannot be pushed across a kinked segment with the normally used guidewire. The attempts to overcome these resistance, may lead to complications as vascular dissection or rupture.

2) partially obstructing and instability guiding catheter Placement of a guiding catheter through a tortuous vessel may result in reduction or occlusion of blood flow (35), increasing the risk of local and distal thromboembolism (36).

Fusionar 3) instability/excessive mobility of the guiding catheter. Besides, even if the kinking is crossed and the guiding catheter is deep-seated in the right position, the catheter partially retains the curvature formed following the vasculature pathway. This is familiar to every interventionalist: the guiding catheter unavoidably drops down and goes back into the aorta. When a catheter inserted in a tortuous vasculature and is either obstructive or mobile beyond suitable limits, additional complications can arise, like dissection or ischemic events. Neuron delivery catheter (Penumbra, Inc., San Leandro, CA) was developed to enable distal catheterization of the intracranial vasculature with added stability and support of the microcatheter, but there are some limitations; The inner diameter of the 
catheter limits the ability to simultaneously advance a second microcatheter in cases such as balloon remodeling during aneurysm treatment. As reported by these authors, there was little success in using this system as initially designed: in general, the 0.018 -inch wire was not robust enough to select the supra-aortic vessels easily.

4) instability/difficult navigation of intracranial devices was another important cause of technical failure. The ability to advance and maintain the stability of additional treatment devices is often a product of guide catheter steadiness (37, 38). Even if the aneurysm is catheterized, the intrasaccular delivery of the coils needs some backup support. For instance, a soft coil can nearly always be passed through the microcatheter into the aneurysm, but sometimes the last loops cannot be deployed because the relatively stiff delivery wire will not negotiate very tortuous arteries (10).

5) difficulties in delivering, deploying and stabilizing an intracranial stent was the last, but not the least important obstacle to overcome. The major benefit of SES is their higher flexibility that allows endovascular access to distal and tortuous arteries (39).

Early published experience with the Neuroform demonstrated higher rates of failure, but newer Neuroform iterations have resulted in some improvement in navigability, but a $4 \%$ inaccurate deployment rate was reported more recently $(4,40)$. Early published experience with Enterprise showed a $2 \%$ inaccurate deployment rate and a 3\% inability-todeploy rate because patients' anatomy (41).

On the other side, when a SES is required, its navigation and deployment require more complex maneuvers, as the stabilizer must be kept in place, while unsheathing stent for deployment. (1) In our previous experience with elongated vessels, the most frequently encountered obstacle was a difficult navigation when using BES. However, the use of newer devices, as the BES Pharos ${ }^{\circledR}$ (Micrus Endovascular, Sunnyvale, CA) allows a smoother navigation in tortuous vessels (6, 42).

Transitory straightening of the Severe tortuosity The straightening of the curved segments would abate these five aforementioned difficulties and enable a navigation involving minimal effort. Most of the anomalies were corrected by the placement of an extra support guidewire alone. The use of a second "buddy guidewire" has recently been introduced to neurointerventional procedures $(15,30,37$, 38) for the purpose of providing more steadiness to the guiding catheter in hostile anatomy. In some cases, this maneuver produces a mechanical distortion of tortuous arteries mimicking spasm or dissection and has been termed as "accordion effect" (43). In our experience This transitory correction is by no means guarantee of a sufficient stability of the whole system.

\section{Correction of the ICA with a stent}

The technique of carotid stenting in this series has progressively evolved. There are two points of fixation of the cervical ICA, a proximal at the bifurcation and a distal at the entry into the pyramid bone (44): a straightening of the kinked segment only can in some cases produce another stentinduced kinking (45) beyond the stented segment (27). In the distal-to-proximal technique, a first stent must be placed and deployed as close as possible to the base of the skull and the following must be deployed with an overlapping technique 
(46) until the full length of the ICA is straight. To achieve an adequate straightening, we consider that two stents are usually sufficient; in cases of severe kinking three stents may be required .

The straightening effects on vascular curves due to a lack of longitudinal flexibility of the Wallstent (45) are desirable in these particular cases. In cases of severe or of double kinking, a distal transfer of a slight curve occurred, but this little "step" did not prevent a farther comfortable navigation (Figure 1). Our target is not the cosmetical result, but the functional result.

\section{Efficacy and complications}

The straightening of the ICA allowed our final End point: a safe navigation of the devices and the treatment of the target lesion in all cases (complex aneurysm).

The technique is not devoid of complications and a stroke occurred in one case. A more rigorous technique of this particular procedure can allow a minimization of the complications. Symptomatic intimal hyperplasia is exceptional, as a less intense inflammatory reaction is expected than in atherosclerotic vessels. We stress on the fact that is an ultimate resource, required only in cases where other maneuvers are more risky or impossible and was not used in a liberal fashion, as only $5,6 \%$ of the total aneurysm have been treated with previous stenting of the cervical ICA.
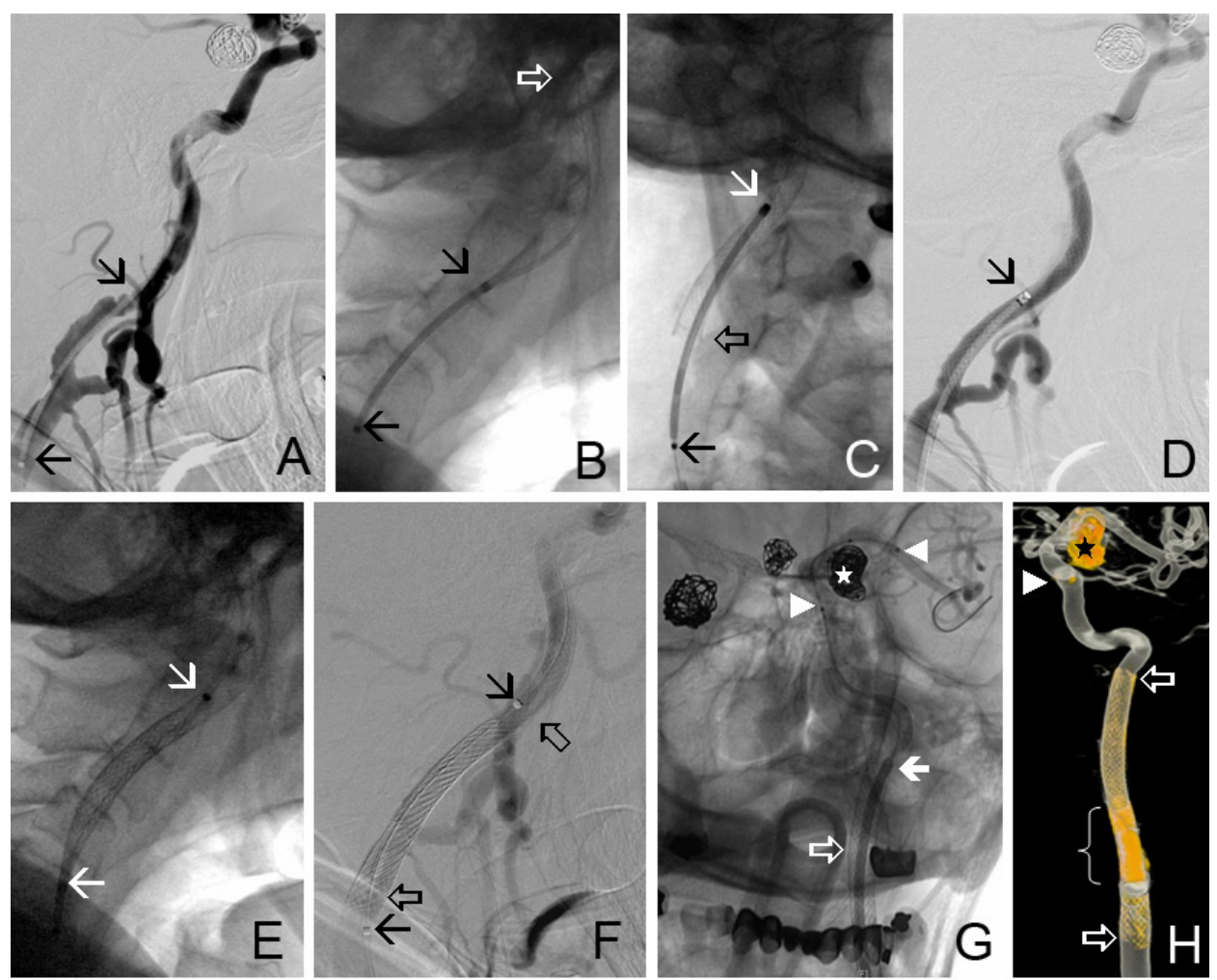

Figure 1

Step by Step of Zenteno Technique of correction of carotid tortuosity 
Other options in case of carotid for the management of severe tortuosity (19, 20, 46, 47, 48)

The surgical cut-down techniques (20) have been used for direct access to the vertebral artery, bypassing the aortic arch and proximal brachiocephalic vessels. It also has been recently applied in severe ICA tortuosity (17). However, as it requires surgical dissection and exposure of the carotid artery, it is not bereft of complications. On the other hand, current regimes of anticoagulant/antiplatelet agents, coupled with demands for large guiding catheters for certain interventions, make direct carotid puncture risky both in terms of arterial injury and control of access site bleeding at the end of the intervention (19).

\section{Limitations of the technique}

All our cases were highly challenging lesions requiring complex procedures and other available resources had failed. The use of an additional device (the carotid stent) can be adduced, but in complex cases, the use of multiple guidewires, the exchange of guiding catheters, the damage of intracranial stents navigated forcefully through this hostile anatomy also represent additional risks and costs, often ending up in an unsuccessful procedure. Antiplatelet treatment is not an issue as most of these patients have an indication for these drugs because of an intracranial stent.

The use of newer technologies may render this procedure unnecessary in the near future. Those devices are not always effective and may be unavailable in some centers. In the meantime, this procedure remains an option which can be used if necessary.

\section{Conclusions}

Tortuous of cervical carotid artery can increase the technical difficulties for a safe navigation of devices when treating aneurysms, especially in cases of assisted techniques. In selected cases, carotid stenting is an effective and relatively safe ancillary tool providing sufficient support guiding catheter. This stability facilitates an eventful and successful procedure, especially when intracranial stent placement is required. Technical refinements include the distal-to-proximal overlapping technique which affords a complete correction and avoids the transferal of the Severe tortuosity beyond the stented segment.

\section{References}

1. Koebbe CJ, Veznedaroglu E, Jabbour P, Rosenwasser RH. Endovascular management of intracranial aneurysms: current experience and future advances. Neurosurgery 2006;59:S93-102; discussion S3-13.

2. Lanzino G, Kanaan Y, Perrini P, Dayoub H, Fraser $\mathrm{K}$. Emerging concepts in the treatment of intracranial aneurysms: stents, coated coils, and liquid embolic agents. Neurosurgery 2005;57:449-59; discussion 44959.

3. Moret J, Cognard C, Weill A, Castaings L, Rey A. The "Remodelling Technique" in the Treatment of Wide Neck Intracranial Aneurysms. Angiographic Results and Clinical Follow-up in 56 Cases. Interv Neuroradiol 1997;3:21-35.

4. Fiorella D, Albuquerque FC, Deshmukh VR, McDougall CG. Usefulness of the Neuroform stent for the treatment of cerebral aneurysms: results at initial (36-mo) follow-up. Neurosurgery 2005;56:1191-201; discussion 1201-2.

5. Howington JU, Hanel RA, Harrigan MR, Levy EI, Guterman LR, Hopkins LN. The Neuroform stent, the first microcatheter-delivered stent for use in the intracranial circulation. Neurosurgery 2004;54:2-5.

6. Zenteno M, Modenesi Freitas JM, Aburto-Murrieta Y, Koppe G, Machado E, Lee A. Balloon-expandable stenting with and without coiling for wide-neck and complex aneurysms. Surg Neurol 2006;66:603-10; discussion 610.

7. Zenteno MA, Santos-Franco JA, Freitas-Modenesi 
JM, Gómez C, Murillo-Bonilla L, Aburto-Murrieta Y, Díaz-Romero R, Nathal E, Gómez-Llata S, Lee A. Use of the sole stenting technique for the management of aneurysms in the posterior circulation in a prospective series of 20 patients. J Neurosurg 2008;108:1104-18.

8. Zenteno M, Santos-Franco J, Aburto-Murrieta Y, Modenesi-Freitas J-M, Ramírez-Guzmán G, GómezLlata S, Lee A. Superior cerebellar artery aneurysms treated using the sole stenting approach. Technical note. J Neurosurg 2007;107:860-4.

9. Zenteno MA, Murillo-Bonilla LM, Guinto G, Gomez CR, Martinez SR, Higuera-Calleja J, Lee A, Gomez-Llata S. Sole stenting bypass for the treatment of vertebral artery aneurysms: technical case report. Neurosurgery 2005;57:E208; discussion E208.

10. Byrne J. Interventional Neuroradiology: Theory and Practice. 1st ed. New York: Oxford University Press; 2002.

11. Murayama Y, Nien YL, Duckwiler G, Gobin YP, Jahan R, Frazee J, Martin N, Viñuela F. Guglielmi detachable coil embolization of cerebral aneurysms: 11 years' experience. J Neurosurg 2003;98:959-66.

12. Nakahara T, Sakamoto S, Hamasaki O, Sakoda K. Double wire technique for intracranial stent navigation. J Vasc Interv Radiol 2003;14:667-8.

13. Pierot L, Boulin A, Castaings L, Rey A, Moret J. Endovascular treatment of pericallosal artery aneurysms. Neurol Res 1996;18:49-53.

14. Blanc R, Deschamps F, Orozco-Vasquez J, Thomas $\mathrm{P}$, Gaston A. A $6 \mathrm{~F}$ guide sheath for endovascular treatment of intracranial aneurysms. Neuroradiology 2007;49:563-6.

15. Lee TH, Choi CH, Park K-P, Sung SM, Lee SW, Lee B-H, Kim DH, Kim HJ, Kim CW, Kim S. Techniques for intracranial stent navigation in patients with tortuous vessels. AJNR Am J Neuroradiol 2005;26:1375-80.

16. Kwon BJ, Han MH, Kang H-S, Jung C. Protection filter-related events in extracranial carotid artery stenting: a single-center experience. J Endovasc Ther 2006;13:711-22.

17. Wehman JC, Hanel RA, Levy EI, Hopkins LN. Giant cerebral aneurysms: endovascular challenges. Neurosurgery 2006;59:S125-38; discussion S3-13.

18. Connors JI, Wojak J, editors. Interventional neuroradiology: strategies and practical techniques. Philadelphia: WB Saunders; 1999.

19. Yuzawa I, Kurata A, Suzuki S, Ozawa H, Hagiwara H, Niki J, Yamada M, Fujii K, Kan S, Kitahara T. Efficacy of a direct puncture approach for anterior circulation aneurysms using a newly developed guiding catheter - especially for geriatric patients. Surg Neurol 2007;67:30-4; discussion 34.

20. Ross IB, Luzardo GD. Direct access to the carotid circulation by cut down for endovascular neuro- interventions. Surg Neurol 2006;65:207-11; discussion 211.

21. Samuelson RM, Yamamoto J, Levy EI, Siddiqui AH, Hopkins LN. The argument to support broader application of extracranial carotid artery stent technology. Circulation 2007;116:1602-10; discussion 1610.

22. Roubin GS, Iyer S, Halkin A, Vitek J, Brennan C. Realizing the potential of carotid artery stenting: proposed paradigms for patient selection and procedural technique. Circulation 2006;113:2021-30.

23. Ringleb PA, Allenberg J, Brückmann H, Eckstein H-H, Fraedrich G, Hartmann M, Hennerici M, Jansen O, Klein G, Kunze A, Marx P, Niederkorn K, Schmiedt W, Solymosi L, Stingele R, Zeumer H, Hacke W. 30 day results from the SPACE trial of stent-protected angioplasty versus carotid endarterectomy in symptomatic patients: a randomised non-inferiority trial. Lancet 2006;368:1239-47.

24. Higashida RT, Meyers PM, Phatouros CC, Connors JJ, Barr JD, Sacks D. Reporting standards for carotid artery angioplasty and stent placement. Stroke 2004;35:e112-34.

25. Hunt WE, Kosnik EJ. Timing and perioperative care in intracranial aneurysm surgery. Clin Neurosurg 1974;21:79-89.

26. Rankin J. Cerebral vascular accidents in patients over the age of 60. II. Prognosis. Scott Med J 1957;2:200-15.

27. Berkefeld J, Martin JB, Théron JG, Zanella FE, Guimaraens L, Treggiari-Venzi MM, Rosendahl H, Rüfenacht DA. Stent impact on the geometry of the carotid bifurcation and the course of the internal carotid artery. Neuroradiology 2002;44:67-76.

28. Metz H, Murray-Leslie RM, Bannister RG, Bull JW, Marshall J. Kinking of the internal carotid artery. Lancet 1961;1:424-6.

29. Togay-Işikay C, Kim J, Betterman K, Andrews C, Meads D, Tesh P, Tegeler C, Oztuna D. Carotid artery tortuosity, kinking, coiling: stroke risk factor, marker, or curiosity? Acta Neurol Belg 2005;105:68-72.

30. Surmely J-F, Cook S. Variation on the Anchor balloon technique for difficult stent delivery. Kardiovaskuläre Medizin 2007;10:397-9.

31. Santos-Franco JA, Zenteno M, Lee A. Dissecting aneurysms of the vertebrobasilar system. A comprehensive review on natural history and treatment options. Neurosurg Rev 2008;31:131-40; discussion 140.

32. Cai Y, Spelle L, Wang H, Piotin M, Mounayer C, Vanzin JR, Moret J. Endovascular treatment of intracranial aneurysms in the elderly: single-center experience in 63 consecutive patients. Neurosurgery 2005;57:1096-102; discussion 1096-102.

33. Lylyk P, Cohen JE, Ceratto R, Ferrario A, Miranda 
C. Angioplasty and stent placement in intracranial atherosclerotic stenoses and dissections. AJNR Am J Neuroradiol 2002;23:430-6.

34. Illuminati G, Ricco J-B, Caliò FG, D'Urso A, Ceccanei G, Vietri F. Results in a consecutive series of 83 surgical corrections of symptomatic stenotic kinking of the internal carotid artery. Surgery 2008;143:134-9.

35. Mathis JM, Zoarski G. Use of a guide catheter as a temporary stent during microcatheter intervention. AJNR Am J Neuroradiol 1998;19:932-3.

36. Tanemura H, Hatazaki S, Asakura F, Kawaguchi K, Kuraishi K, Toma N, Sakaida H, Maeda M, Taki W. Angioscopic observation during carotid angioplasty with stent placement. AJNR Am J Neuroradiol 2005;26:1943-8.

37. Nishino K, Ito Y, Hasegawa H, Kikuchi B, Fujii Y, Tanaka R. Modified buddy wire technique for coil embolization of posterior circulation aneurysms. Neuroradiology 2007;49:49-55.

38. White JB, Kallmes DF. Utility of the "buddy" wire in intracranial procedures. Neuroradiology 2008;50:185-7.

39. Kis B, Weber W, Berlit P, Kühne D. Elective treatment of saccular and broad-necked intracranial aneurysms using a closed-cell nitinol stent (Leo). Neurosurgery 2006;58:443-50; discussion 443-50. 40. Biondi A, Janardhan V, Katz JM, Salvaggio K, Riina HA, Gobin YP. Neuroform stent-assisted coil embolization of wide-neck intracranial aneurysms: strategies in stent deployment and midterm follow-up. Neurosurgery 2007;61:460-8; discussion 468-9.

41. Mocco J, Snyder K V, Albuquerque FC, Bendok BR, Alan S B, Carpenter JS, Fiorella DJ, Hoh BL, Howington JU, Jankowitz BT, Liebman KM, Rai AT, Rodriguez-Mercado R, Siddiqui AH, Veznedaroglu E, Hopkins LN, Levy EI. Treatment of intracranial aneurysms with the Enterprise stent: a multicenter registry. J Neurosurg 2009;110:35-9.

42. Freitas JMM, Zenteno M, Aburto-Murrieta Y, Koppe G, Abath C, Nunes JA, Raupp E, Hidalgo R, Pieruccetti MA, Lee A. Intracranial arterial stenting for symptomatic stenoses: a Latin American experience. Surg Neurol 2007;68:378-86.

43. Tsutsumi M, Kazekawa K, Onizuka M, Aikawa H, Iko M, Kodama T, Nii K, Matsubara S, Etou H, Tanaka A. Accordion effect during carotid artery stenting: report of two cases and review of the literature.
Neuroradiology 2007;49:567-70.

44. Székely G, Csécsei GI. Anteposition of the internal carotid artery for surgical treatment of kinking. Surg Neurol 2001;56:124-6.

45. Tanaka N, Martin J-B, Tokunaga K, Abe T, Uchiyama Y, Hayabuchi N, Berkefeld J, Rüfenacht DA. Conformity of carotid stents with vascular anatomy: evaluation in carotid models. AJNR Am J Neuroradiol 2004;25:604-7.

46. Lesley WS, Weigele JB, Chaloupka JC. Outcomes for overlapping stents in the extracranial carotid artery. Catheter Cardiovasc Interv 2004;62:375-9.

47. Gavrilenko AV, Abramian AV, Kuklin AV. Comparative analysis of the outcomes of surgical and conservative treatment of patients with pathological kinking of carotid arteries. Angiol Sosud Khir. 2012;18(4):93-9

48. Cong TC, Duan X, Gao WH, Zhao EM, Yang XD, Wang H, Xiao SF, Qin Y.Tortuosity and kinking of cervical segment of internal carotid artery: an analysis of 7 cases. Zhonghua Er Bi Yan Hou Tou Jing Wai Ke Za Zhi. 2012 Nov;47(11):913-7.

49. Pokrovskiı̌ AV, Beloiartsev DF, Adyrkhaev ZA, Timina IE, Losik IA. Remote results of reconstructive operations in pathological deformity of the internal carotid artery. Angiol Sosud Khir. 2012;18(1):92-104. 50. Cohen JE, Gomori JM, Leker RR, Itshayek E.A reappraisal of the common carotid artery as an access site in interventional procedures for acute stroke therapies. J Clin Neurosci. 2012 Feb;19(2):323-6

51. Pokrovskiı̌ AV, Beloiartsev DF, Timina IE, Adyrkhaev ZA. Clinical manifestations and diagnosis of pathological deformity of the internal carotid artery. Angiol Sosud Khir. 2011;17(3):7-18

52. Derubertis BG, Hynecek RL, Kent KC, Faries PL. Carotid tortuosity in patients with prior cervical radiation: increased technical challenge during carotid stenting. Vasc Endovascular Surg. 2011 Oct;45(7):61926.

53. Hosokawa S, Mineta H. Tortuous internal carotid artery presenting as a pharyngeal mass. J Laryngol Otol. 2010 Sep;124(9):1033-6.

54. Robert V Carlson, Kenneth M Boyd,1 and David J Webb. The revision of the Declaration of Helsinki: past, present and future $\mathrm{Br} \mathrm{J}$ Clin Pharmacol. 2004 June; 57(6): 695-713. 